\title{
THE ACUTE CIRCULATORY EFFECTS OF THE HEAD-DOWN \\ POSITION (NEGATIVE G) IN NORMAL MAN, WITH A \\ NOTE ON SOME MEASURES DESIGNED TO RE- LIEVE CRANIAL CONGESTION IN THIS POSITION ${ }^{1}$
}

\author{
BY ROBERT W. WILKINS, STANLEY E. BRADLEY, ${ }^{2}$ AND CARL K. FRIEDLAND ${ }^{8}$ \\ (From the Robert Daweson Evans Memorial, Massachusetts Memorial Hospitals, and the De- \\ partment of Medicine, Boston University School of Medicine, Boston, Mass.)
}

(Submitted for publication January 12, 1950; accepted, April 3, 1950)

Although many individuals have experienced briefly the sensation of hanging head downwards, relatively little is known of the physiology of the inverted position. This lack of knowledge may be attributed to the apparent unimportance of the position, which until recently was almost never assumed except by children or acrobats. With the development of air warfare, however, the action of all types of centrifugal and gravitational force ("G") upon human physiology became important. Much study was devoted to the effects of the headto-foot (positive) "G" frequently experienced in aircraft as a result of the radial acceleration of inside loops or turns. Comparatively little attention was paid to the less common foot-to-head (negative) "G" encountered during outside loops or turns, although it was known to cause symptoms, such as "redding-out," headache and/or confusion.

Studies of the effects of upright tilting $(+1 \mathrm{G})$ had proved helpful in clarifying the basic physiology of positive $G$ in aircraft, where the forces frequently may attain values of eight to ten times the pull of the earth. Similar studies of head-down tilting seemed even more pertinent because this maneuver more closely approximates the maximum $(-3$ to -4$)$ negative $G$ likely ever to be encountered. Therefore, the present investigation was undertaken to establish the basic pattern of the circulatory changes in man during the imposition of $-1 \mathrm{G}$, produced by tilting the subject into

1 This work was carried out under a contract between the Massachusetts Memorial Hospitals and the Office of Scientific Research and Development.

2 Present address: Columbia University, College of Physicians and Surgeons, New York, N. Y.

3 Present address: University of Pennsylvania, School of Medicine, Hospital of the University of Pennsylvania, Philadelphia. the head-down position. The results have been reported in restricted form (1), and were to have been published in a generally available "Monograph on Acceleration," a project which unfortunately had to be abandoned. However, recent interest in the physiology of the head-down position (2) has seemed to justify the publication of this material through regular channels, even at this late date after its completion.

\section{SUBJECTS AND METHODS}

Forty-two (forty male, two female), afebrile, normotensive hospital patients, convalescent from minor ailments were studied in the head-down position as compared with the supine resting state or the head-up posture. On 64 occasions, a change of approximately $-1 \mathrm{G}$ was produced by a quick (one to three second) manual shift from the horizontal to the head-down $\left(-75^{\circ}\right)$ position. In 96 instances, a change of approximately $-2 \mathrm{G}$ was produced by tilting from the upright $\left(+75^{\circ}\right)$ posture (held for at least two minutes) quickly down through an angle of $150^{\circ}$, to the inverted $\left(-75^{\circ}\right)$ position. The head-down position was maintained for two to 30 minutes depending upon the nature of the measurements being made, and the ability of the subject to tolerate the position. The control horizontal position was then resumed for at least ten minutes before tilting again.

The arterial pressure was measured with a needle in the brachial 4 and/or femoral artery, attached by a short length of relatively indistensible, but flexible, venous catheter ${ }^{5}$ to lead tubing, and thence to a Hamilton manometer (3) firmly fixed to an optical bench. On eight occasions simultaneous measurements of the right atrial pressure (4) were made through a longer venous catheter attached to a Hamilton manometer. In 15 instances venous pressure was measured similarly except that the catheter was passed into the internal jugular vein to about the level of the base of the skull. All meas-

4 The arm was kept in the anatomical position (the frontal plane), slightly abducted from the body.

$5 \mathrm{U}$. S. Catheter and Instrument Corporation, Glen Falls, New York. 
urements of blood pressure were made in $\mathrm{mm}$. $\mathrm{Hg}$ above atmospheric pressure and related in space to the level of the tip of the needle or catheter both in the horizontal and tilted positions. Ballistocardiograms were recorded during separate experiments on six subjects in the horizontal, head-up $\left(+75^{\circ}\right)$ and head-down $\left(-75^{\circ}\right)$ positions using the tilting ballistocardiograph (5). Cardiac outputs were calculated from the corrected area formula of Starr (6).

In ten additional subjects the glomerular filtration rate and renal plasma flow were measured by the inulin or mannitol, and the diodrast or sodium para-aminohippurate (PAH) clearance methods (7), respectively, before, during, and after tilting into the head-down position. ${ }^{6} \mathrm{~A}$ multiple-eyed urethral catheter was placed in the bladder and urine collected at ten to 20 minute intervals. On each occasion the bladder was emptied by manual compression and washed out with a measured volume of isotonic saline solution and air, according to the customary procedure, and the volume of urine carefully measured. Plasma concentrations of the various test substances recommended by Goldring and Chasis (7) were established and maintained by appropriate priming and sustaining infusions. The concentrations of mannitol or inulin, and diodrast or sodium para-aminohippurate were determined on cadmium filtrates of plasma and aliquots of diluted urine using the methods outlined by Goldring and Chasis (7). An effort was made to obtain three successive clearance values before, during, and after tilting, but on several occasions only one or two periods could be obtained in the head-down position, owing to the discomfort experienced in this position. These studies were carried out in the $-75^{\circ}$ inverted position in only four cases because this position could not be maintained comfortably for the period of time necessary for accurate measurement, and, in addition, made complete emptying of the

6 We are indebted to Dr. W. P. Boger and to Sharpe \& Dohme, Inc., Philadelphia, for a generous supply of mannitol and sodium para-aminohippurate. bladder difficult. Consequently, a $-30^{\circ}$ or $-40^{\circ}$ headdown position was used in the rest of the tests.

\section{RESULTS}

\section{Subjective symptoms in the head-down position}

In the present study, two shoulder supports, well-padded with thick felt and sponge rubber, supported the weight of the body in the inverted position. On tilting quickly head-downwards there was an immediate sensation of tumbling heels-overhead, with a tensing of the body musculature, and a tendency to grip the sides of the table. Strapping the thighs to the table allayed the fear, but failed to produce complete muscular relaxation. At first the shoulders seemed comfortable, but within a minute or two the pressure upon them became increasingly painful. Breathing was interfered with, making accurate measurement of vital capacity impossible.

Circulatory symptoms noted subjectively during and immediately after the head-down tilt included a sense of facial congestion and cranial swelling which increased rapidly during the first few seconds, and slowly thereafter. The face felt warm and flushed, whereas the feet grew cold and clammy. The nasal mucosa became congested, producing partial or total obstruction, associated in some subjects with a profuse postnasal accumulation of secretions. After a minute or less, perspiration appeared over the neck and face, and tears began to flow from the eyes. On return to the horizontal position, the symptoms of cranial congestion cleared rapidly, but an unpleasant tingling of the feet set in.

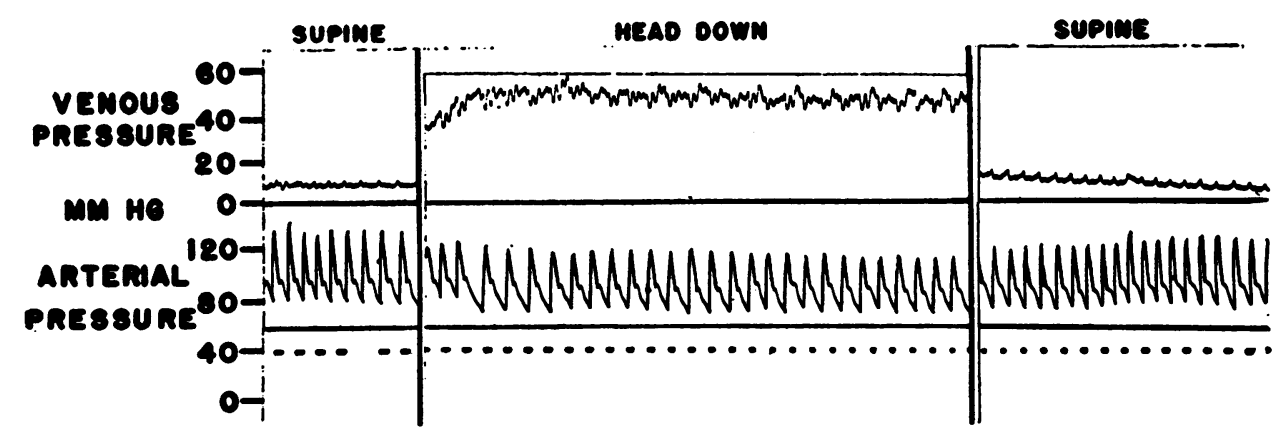

Fig. 1. Optical (Hamilton) Record of Internal Jugular Venous Pressure (Upper

Tracing) and Brachial Arterial Pressure (Middle Tracing) in a Normal Subject

The interrupted horizontal line below indicates seconds. At the first heavy vertical line the subject was tilted quickly into the inverted $\left(75^{\circ}\right)$ position, and at the second, back to the horizontal. 


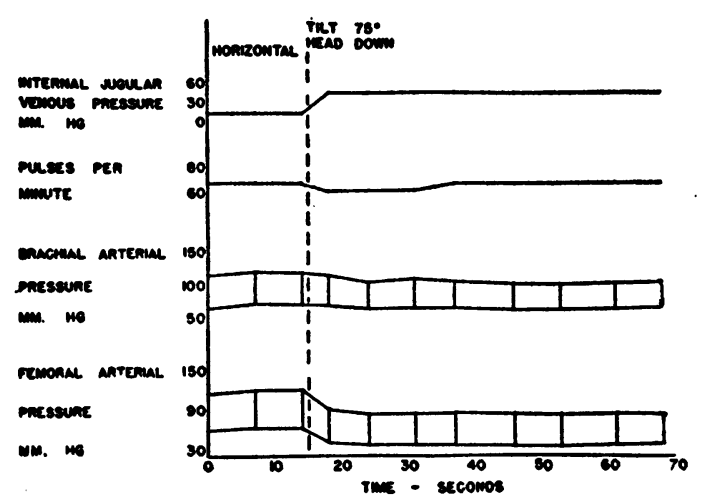

Fig. 2. Graph of Internal Jugular Venous Pressure, Pulse Rate, Brachial Arterial Pressure and Femoral Arterial Pressure in a Normal Subject

At the vertical interrupted line he was tilted into an inverted position $\left(75^{\circ}\right)$.

Effect of the head-down position on arterial pressure

Changes in arterial pressure on assuming the head-down posture were measured in 18 subjects on 80 occasions, 26 of which followed tilting from the horizontal position, the remainder from the upright position. In three subjects femoral and brachial arterial pressures were recorded simultaneously; in four, only the femoral arterial pressure was measured; and in the remainder, only the brachial.

When the subject was tilted quickly head-down from horizontal (Figures 1,2), there was usually an immediate change in arterial pressure, followed by a brief, fairly stable plateau for two or three pulse beats. The immediate shift in pressure was especially marked in the femoral artery, where there was always a fall, and was less pronounced in the brachial, where there was usually a rise (especially in diastolic pressure) (Figure 1), or no change (Figure 2). This first shift in pressure was assumed to be due to passive hydrostatic effects of the new position, since it was immediate and equal in the femoral and brachial arteries except for differences in their hydrostatic levels. After a few pulse beats there was usually a gradual slight decline in pressure in both arteries, associated with slowing, and often irregularity, of the pulse. This secondary decrease in pressure required five to 15 seconds, after which pressure became stabilized at a lower level, while pulse rate increased moderately toward, or occasionally to, the previous resting (horizontal) levels.

From the above observations it was clear that the point or level in the body where arterial pressure (as calculated by the hydrostatic distances) was the same in the head-down as in the horizontal position (zero reference point), was different immediately after a quick tilt, as compared with some seconds later. Immediately, this point was usually near the brachial arterial needle, at about the level of the diaphragm or slightly footward of it. Later, after the ensuing vasodepressor response, it had

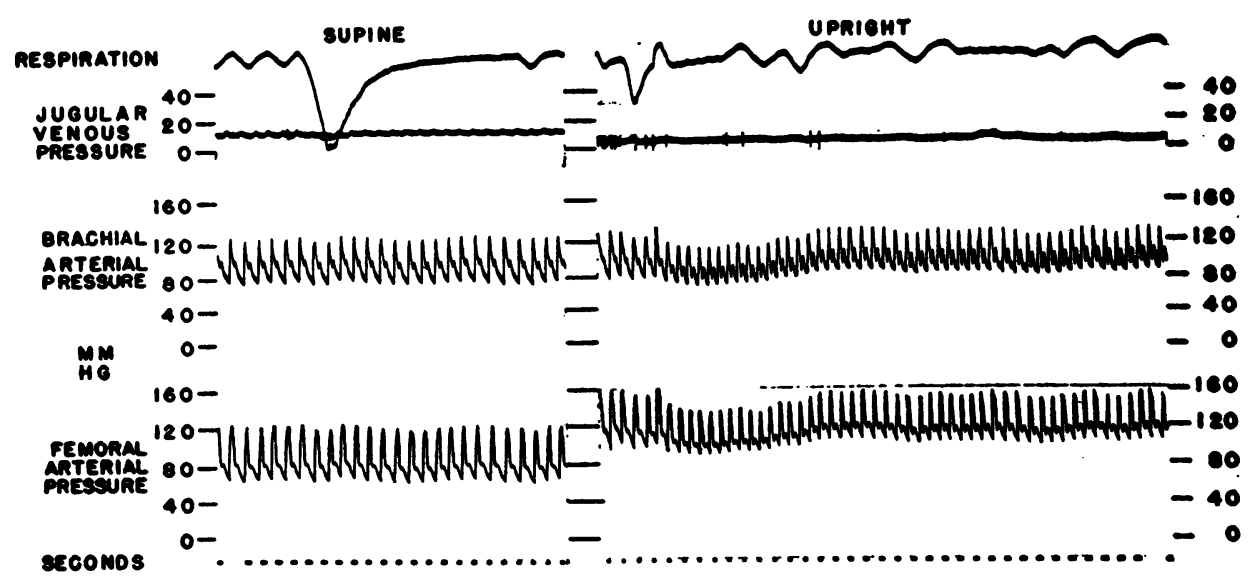

Fig. 3. Optical Record of Respiration (Inspiration Downwards), Internal Jugular Venous Pressure, Brachial Arterial Pressure and Femoral Arterial Pressure in a Normal SUbJEct

The interrupted horizontal line below indicates seconds. At the gap in the record the subject was tilted from the horizontal to the vertical $\left(75^{\circ}\right)$ position. 


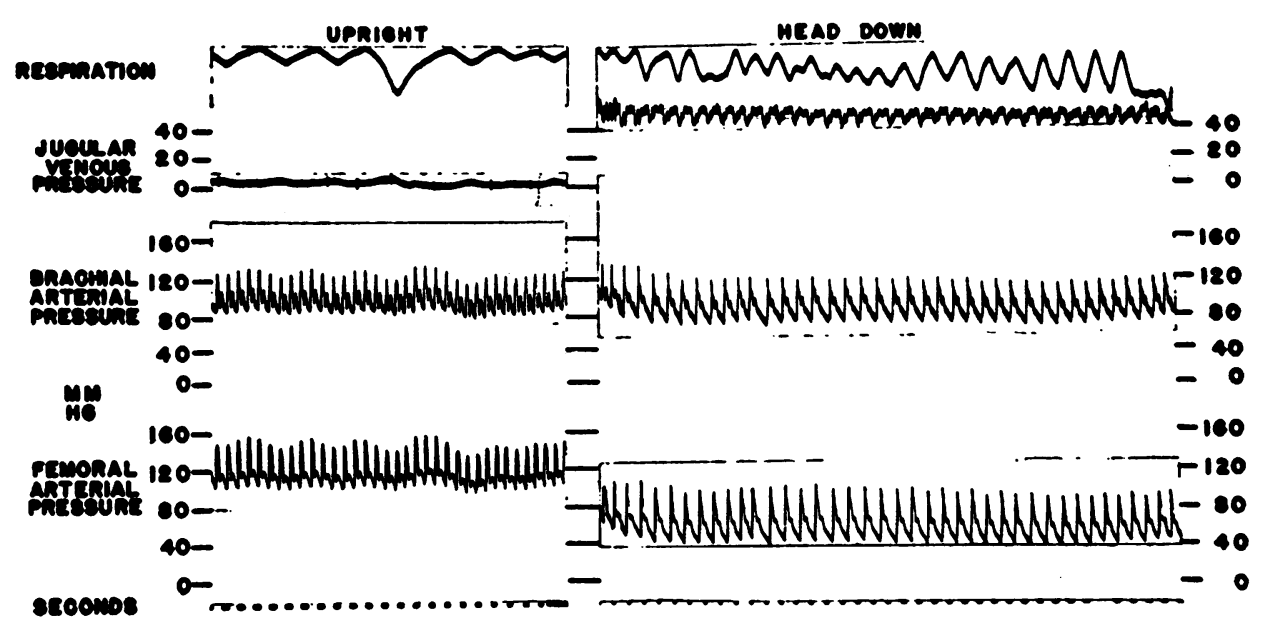

Fig. 4. Optical Record of Respiration (Inspiration Downwards), Internal Jugular Pressure, Brachial Arterial Pressure and Femoral Arterial Pressure in a Normal SubJect

The interrupted horizontal line below indicates seconds. At the gap in the record the subject was tilted quickly from upright into the inverted $\left(75^{\circ}\right)$ position.

shifted nearer the head, to a level about that of the arch of the aorta. Further investigation of these zero reference points was necessary to clarify their possible significance, and will form the subject of a separate communication (8).

When tilted quickly head-down from the upright position (Figure 4), the acute changes in arterial pressure and pulse rate were qualitatively similar to, but quantitatively greater than, those just described. This was due principally to the fact that the preliminary assumption of the upright position from the horizontal had been followed by opposite effects (Figure 3 ). Thus, on tilting from horizontal to upright, there was an immediate "hydrostatic" change, especially in the femoral artery, where pressure rose. After several pulse beats at the new level, pressure began to fall, systolic more than diastolic, and pulse rate to rise. There was then a slow rise in arterial pressure, diastolic usually more than systolic, with narrowing of the pulse pressure. This secondary rise, which was attributed to systemic vasoconstriction, failed to appear in rare individuals with poor postural adjustment to the erect position who instead suffered a progressive fall in the arterial pressure to low levels, with syncope. After adjustment to the erect posture, arterial pressure and pulse rate remained essentially unchanged, except for the appearance of marked, slow phasic fluctuations in the arterial pressure. These were but ex- aggerations of variations usually discernible in the arterial pressure during recumbency.

Following relative stabilization of the circulation in the upright position, the subject was quickly tilted head-down (Figure 4). Again immediate alterations in arterial pressure appeared with a marked fall in femoral, and a moderate rise in the brachial pressure, presumably the result of passive hydrostatic effects. After several pulse beats the cardiac cycle was lengthened and there was a decrease in pressure, first diastolic and then systolic. The pulse rate, which had ranged from 90-100 decreased to $44-68$ beats per minute, and was often markedly irregular. This depressor phase, though longer in duration, frequently resulted in lowering the arterial pressure less than the depressor phase that occurred after tilting the same subject head-down from horizontal. However, arterial pressure finally became stabilized, and the pulse rate returned toward the resting level.

In addition to the changes of arterial pressure noted above, alterations in the form of the arterial pulse waves were observed following tilting. In the upright position the waves became sharply peaked, and the dicrotic notches tended to arise lower on them (Figure 3). Following inversion, the dicrotic notches arose higher on the waves, and in the brachial arterial tracing at times reached levels as high as the systolic peaks. 


\section{Effects of the head-down position upon internal jugular venous pressure}

Pressure was measured in the internal jugular vein of 15 subjects before and after tilting into the head-down position on 93 occasions. All tracings possibly inaccurate because of leakage, vibration or questionable calibration were excluded from quantitative analysis, although they were not qualitatively dissimilar from the rest. Of the remaining 57 head-down tilts in 12 subjects, 34 followed a preliminary period of orthostasis, and 23 were from the horizontal position. In the upright position (Table I, Figure 3), the jugular pressure always fell to or slightly below zero, a finding confirming the visible collapse of the neck veins. After quickly tilting from upright or horizontal

TABLE I

Internal jugular venous pressure in different postures*

\begin{tabular}{|c|c|c|c|c|c|c|}
\hline \multirow{3}{*}{ Subject } & \multirow{3}{*}{$\begin{array}{c}\text { Position } \\
\text { prior to } \\
\text { inversion }\end{array}$} & \multirow{3}{*}{$\begin{array}{l}\text { Thigh } \\
\text { cuffs }\end{array}$} & \multicolumn{4}{|c|}{$\begin{array}{l}\text { Internal jugular venous pressure } \\
\qquad \begin{array}{l}\mathrm{mm} \\
\mathrm{Hg}\end{array}\end{array}$} \\
\hline & & & \multirow{2}{*}{ Control } & \multicolumn{2}{|c|}{ Head-down } & \multirow{2}{*}{$\begin{array}{l}\text { Recover } \\
\text { (supine) }\end{array}$} \\
\hline & & & & $\begin{array}{l}10 \text { to } 20 \\
\text { seconds }\end{array}$ & $\begin{array}{l}30 \text { to } 60 \\
\text { seconds }\end{array}$ & \\
\hline J. H. & $\begin{array}{l}\text { Horizontal } \\
\text { Upright } \\
\text { Upright }\end{array}$ & $\begin{array}{l}\text { off } \\
\text { off } \\
\text { on }\end{array}$ & $\begin{array}{r}12 \\
0 \\
-5\end{array}$ & $\begin{array}{l}44 \\
47 \\
38\end{array}$ & $\begin{array}{l}43 \\
43 \\
30\end{array}$ & $\begin{array}{l}12 \\
10 \\
10\end{array}$ \\
\hline A. 0. & $\begin{array}{l}\text { Horizontal } \\
\text { Horizontal } \\
\text { Upright } \\
\text { Upright }\end{array}$ & $\begin{array}{l}\text { off } \\
\text { on } \\
\text { off } \\
\text { on }\end{array}$ & $\begin{array}{l}8 \\
8 \\
4 \\
4\end{array}$ & $\begin{array}{l}37 \\
31 \\
40 \\
29\end{array}$ & $\begin{array}{l}36 \\
29 \\
40 \\
30\end{array}$ & $\begin{array}{r}10 \\
11 \\
12 \\
8\end{array}$ \\
\hline D. B. & $\begin{array}{l}\text { Horizontal } \\
\text { Horizontal }\end{array}$ & $\begin{array}{l}\text { off } \\
\text { on }\end{array}$ & $\begin{array}{l}4 \\
0\end{array}$ & $\begin{array}{l}27 \\
23\end{array}$ & $\begin{array}{l}18 \\
17\end{array}$ & $\begin{array}{l}0 \\
5\end{array}$ \\
\hline P. C. & $\begin{array}{l}\text { Horizontal } \\
\text { Horizontal } \\
\text { Upright } \\
\text { Upright }\end{array}$ & $\begin{array}{l}\text { off } \\
\text { on } \\
\text { off } \\
\text { on }\end{array}$ & $\begin{array}{r}7 \\
7 \\
-8 \\
-9\end{array}$ & $\begin{array}{l}45 \\
35 \\
50 \\
38\end{array}$ & $\begin{array}{l}40 \\
32 \\
50 \\
34\end{array}$ & $\begin{array}{l}7 \\
5 \\
7 \\
5\end{array}$ \\
\hline H. S. & $\begin{array}{l}\text { Horizontal } \\
\text { Horizontal }\end{array}$ & $\begin{array}{l}\text { off } \\
\text { on }\end{array}$ & $\begin{array}{r}4 \\
-5\end{array}$ & $\begin{array}{l}50 \\
38\end{array}$ & $\begin{array}{l}50 \\
34\end{array}$ & -5 \\
\hline A. A. & $\begin{array}{l}\text { Horizontal } \\
\text { Horizontal } \\
\text { Upright } \\
\text { Upright }\end{array}$ & $\begin{array}{l}\text { off } \\
\text { on } \\
\text { off } \\
\text { on }\end{array}$ & $\begin{array}{l}-1 \\
-1 \\
-3 \\
-3\end{array}$ & $\begin{array}{l}24 \\
20 \\
30 \\
10\end{array}$ & $\begin{array}{l}26 \\
18 \\
29 \\
15\end{array}$ & $\begin{array}{l}0 \\
1 \\
2 \\
2\end{array}$ \\
\hline R. J. & $\begin{array}{l}\text { Horizontal } \\
\text { Upright } \\
\text { Upright }\end{array}$ & $\begin{array}{l}\text { off } \\
\text { off } \\
\text { on }\end{array}$ & $\begin{array}{r}6 \\
1 \\
-5\end{array}$ & $\begin{array}{l}15 \\
30 \\
15\end{array}$ & $\begin{array}{l}11 \\
33 \\
34\end{array}$ & $\begin{array}{l}3 \\
8 \\
7\end{array}$ \\
\hline J. K. & $\begin{array}{l}\text { Horizontal } \\
\text { Upright }\end{array}$ & $\begin{array}{l}\text { off } \\
\text { off }\end{array}$ & $\begin{array}{l}8 \\
0\end{array}$ & $\begin{array}{l}38 \\
38\end{array}$ & $\begin{array}{l}33 \\
38\end{array}$ & $\begin{array}{l}10 \\
12\end{array}$ \\
\hline
\end{tabular}

* These data were selected from representative experiments complete enough to allow accurate comparisons to be made of internal jugular venous pressure in each posture, with or without the application of congesting cuffs on the thighs.

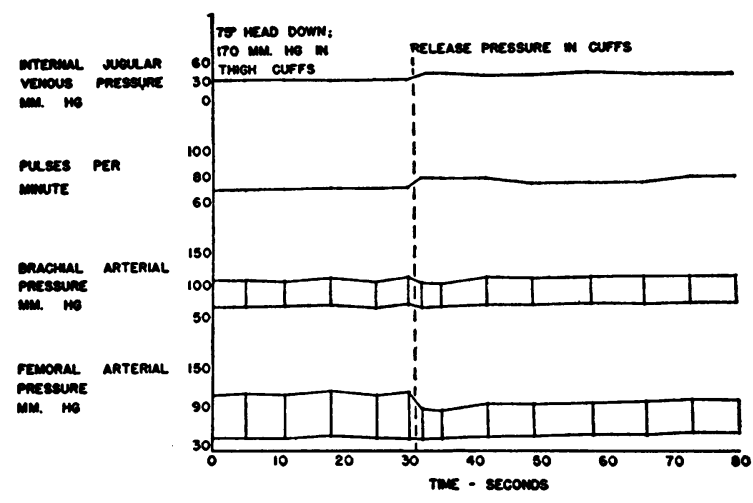

Fig. 5. Graph of Internal Jugular Venous Pressure, Pulse Rate, Brachial Arterial Pressure, and Femoral Arterial Pressure in a Normal Subject in THE INVERTed $\left(75^{\circ}\right)$ Position

At the vertical interrupted line, cuffs on the thighs inflated prior to the tilt at a suprasystolic pressure were deflated.

into the head-down position, the jugular venous pressure usually rose immediately by 15 to 30 millimeters of mercury, and then continued to rise a similar amount, though not as rapidly, during the course of the next few seconds (Figure 1). The first of these early changes was found only after quick (one second) inversions and was attributed to immediate hydrostatic effects, while the second was believed due to the drainage of blood from the elevated parts into the dependent venous chambers. Often, with slower tilts, these two phases were merged into a single smooth rise in pressure as the subject was tilted. They were followed by a period of relatively stable pressure, except for the appearance of marked venous (cardiac) pulsations and (usually) a slow, gentle decline in the basic pressure level (Figure 1).

The influence of venous return from infradiaphragmatic regions upon the early post-tilt levels of pressure in supradiaphragmatic veins during inversion was shown by the following experiments: 1) the internal jugular venous pressure was lower if venous return from the legs was prevented by the inflation of obstructing cuffs on the thighs before tilting into the head-down position (Table I) ; 2) it rose quickly upon release of such cuffs (Figure 5);3) it was higher if the inversion followed a period of orthostasis long enough to allow a considerable volume of blood to pool in the veins of the lower extremities (Table I). The actual level of pressure attained in the internal 
jugular vein after several minutes in the headdown position was roughly equivalent to that which would be exerted hydrostatically by a column of blood extending upward to, or but slightly caudad of, the right atrium. It seemed important, therefore, to determine the changes in atrial pressure.

\section{Effects of the head-down position upon right atrial pressure}

Right atrial pressure was measured in eight individuals during 22 inversions, half of which followed periods of orthostasis. For technical reasons the data derived in the study of three subjects, including seven of the 22 inversions, were excluded from quantitative analysis although they showed qualitatively the same trends as the others. In general, the changes in atrial pressure in the head-down position resembled those in internal jugular pressure if allowance be made for differences in hydrostatic levels between the two points (Table II). Thus, on tilting head-down quickly,

TABLE II

Right atrial pressure $(\mathrm{mm} . \mathrm{Hg})$ in different postures

\begin{tabular}{|c|c|c|c|c|c|c|c|}
\hline \multirow{2}{*}{ Subject } & \multirow{2}{*}{$\begin{array}{l}\text { Test } \\
\text { no. }\end{array}$} & \multirow{2}{*}{$\begin{array}{c}\text { Control } \\
\text { (supine) }\end{array}$} & \multicolumn{2}{|c|}{ Upright } & \multicolumn{2}{|c|}{ Head-down } & \multirow{2}{*}{$\begin{array}{l}\text { Recovery } \\
\text { (supine) }\end{array}$} \\
\hline & & & $\begin{array}{c}10-20 \\
\text { sec. }\end{array}$ & $\begin{array}{c}30-60 \\
\text { sec. }\end{array}$ & $\begin{array}{c}10-20 \\
\text { sec. }\end{array}$ & $\begin{array}{c}30-60 \\
\text { sec. }\end{array}$ & \\
\hline A. $\mathrm{K}$. & $\begin{array}{l}1 \\
2\end{array}$ & $\begin{array}{r}12 \\
9\end{array}$ & $\begin{array}{l}9 \\
6\end{array}$ & $\begin{array}{l}8 \\
5.5\end{array}$ & $\begin{array}{l}20 \\
12\end{array}$ & $\overline{12}$ & $\begin{array}{l}8 \\
8\end{array}$ \\
\hline J. A. & $\begin{array}{l}1 \\
2\end{array}$ & $\begin{array}{r}7 \\
14\end{array}$ & $\begin{array}{l}\mathbf{0} \\
\mathbf{0}\end{array}$ & $\begin{array}{l}0 \\
2\end{array}$ & $\begin{array}{l}18 \\
19\end{array}$ & $\begin{array}{r}15 \\
9\end{array}$ & $\begin{array}{r}7 \\
20\end{array}$ \\
\hline R. W. & $\begin{array}{l}1 \\
2\end{array}$ & $\begin{array}{l}11 \\
11\end{array}$ & $\begin{array}{l}-4 \\
-1\end{array}$ & $\begin{array}{l}-4 \\
-3\end{array}$ & $\begin{array}{l}23 \\
27\end{array}$ & $\begin{array}{l}23 \\
18\end{array}$ & $\begin{array}{l}11 \\
10\end{array}$ \\
\hline I. $\mathrm{H}$. & $\begin{array}{r}1 \\
2 \\
* 3 \\
+4 \\
5\end{array}$ & $\begin{array}{r}12 \\
10 \\
9 \\
8 \\
10\end{array}$ & 6 & 5 & $\begin{array}{r}10 \\
10 \\
8 \\
15 \\
18\end{array}$ & $\begin{array}{l}9 \\
7 \\
0 \\
6 \\
8\end{array}$ & $\begin{array}{r}10 \\
9 \\
8 \\
9 \\
9\end{array}$ \\
\hline L. B. & $\begin{array}{r}1 \\
* 2 \\
3 \\
4\end{array}$ & $\begin{array}{r}15 \\
7 \\
15 \\
9\end{array}$ & $\begin{array}{r}10 \\
8\end{array}$ & $\begin{array}{r}10 \\
9\end{array}$ & $\begin{array}{l}20 \\
12 \\
22 \\
18\end{array}$ & $\begin{array}{r}15 \\
0 \\
14 \\
0\end{array}$ & $\frac{15}{15}$ \\
\hline
\end{tabular}

* Cuffs applied to the thighs at pressures sufficient to cause venous occlusion at the moment of inversion.

t Cuffs applied to the thighs at occlusive pressures several minutes prior to tilting, and released at the moment of inversion.

These data were selected from representative experiments complete enough to allow accurate comparisons to be made of right atrial pressure in each posture.

Omission of figures under Upright indicates that tilting was directly from the horizontal to head-down.

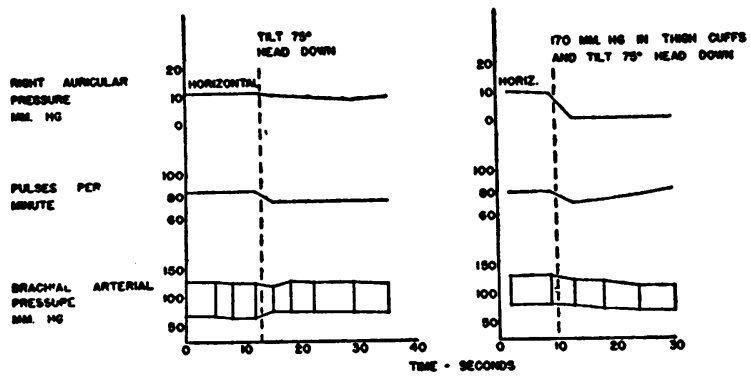

Fig. 6. Graph of Right Atrial Pressure, Pulse Rate, and Brachial Arterial Pressure in a Normal SubJeCT

At the vertical interrupted lines the subject was tilted from a horizontal into an inverted $\left(75^{\circ}\right)$ position. The experiment on the left is the control; that on the right shows the effects of inflating cuffs on the thighs to a suprasystolic pressure at the instant of the inversion.

there was usually an immediate fall (instead of a rise) in atrial pressure of 15 to 20 millimeters of mercury, followed by a rapid rise, then a leveling off, with a tendency to a slow, gentle decline. When the tilt was performed more slowly, the initial fall in pressure was slight and smooth, with no secondary rise (Figure 6). The early posttilt levels of pressure in the right atrium, as in the jugular vein, were higher if the inversion followed a preliminary period of orthostasis, and lower when it occurred during a period of venous arrest or congestion in the legs produced by the inflation of blood pressure cuffs around the thighs (Figure 6). Release of the obstructing cuffs on the thighs during the head-down tilt was followed by a rapid rise of 5 to 15 millimeters of mercury in atrial pressure, as in jugular pressure. These direct measurements confirmed the impressions of Asmussen and coworkers derived from estimations of vital capacity and "central venous pressure" (Henderson) in the head-down position (9).

Atrial pressure was always lower in the upright position than in the horizontal position. Likewise, it was frequently lower in the headdown position than in the horizontal position. Apparently the atrial pressure in the inverted position was not subject to the full imposition of the hydrostatic effects of blood in venous columns caudad to the diaphragm. On the other hand, the fact that atrial pressure in this position was not wholly independent of venous return from areas caudad to the heart was clearly shown by the decrease in pressure found when venous obstruction 
TABLE III

Cardiac output in different postures

\begin{tabular}{|c|c|c|c|c|c|c|c|c|c|}
\hline \multirow[b]{2}{*}{ Subject } & \multicolumn{3}{|c|}{ Recumbent } & \multicolumn{3}{|c|}{ Upright* } & \multicolumn{3}{|c|}{ Head-down } \\
\hline & $\begin{array}{c}\text { Pulse } \\
\text { rate } \\
\text { per min. }\end{array}$ & $\begin{array}{c}\text { Stroke } \\
\text { volume }\end{array}$ & $\begin{array}{c}\text { Cardiac } \\
\text { output }\end{array}$ & $\begin{array}{c}\text { Pulse } \\
\text { rate } \\
\text { per min. }\end{array}$ & $\begin{array}{c}\text { Stroke } \\
\text { volume }\end{array}$ & $\begin{array}{l}\text { Cardiac } \\
\text { output }\end{array}$ & $\begin{array}{l}\text { Pulse } \\
\text { rate } \\
\text { per min. }\end{array}$ & $\begin{array}{l}\text { Stroke } \\
\text { volume }\end{array}$ & $\begin{array}{l}\text { Cardiac } \\
\text { output }\end{array}$ \\
\hline $\begin{array}{l}\text { D. } \\
\text { G. } \\
\text { T. } \\
\text { F. } \\
\text { S. }\end{array}$ & $\begin{array}{r}85 \\
91 \\
69 \\
70 \\
67 \\
\mp 76\end{array}$ & $\begin{array}{l}c c . \\
37 \\
43 \\
61 \\
71 \\
88 \\
51\end{array}$ & $\begin{array}{c}\text { l. per min. } \\
3.2 \\
4.0 \\
4.2 \\
5.0 \\
5.7 \\
3.9\end{array}$ & $\begin{array}{r}77 \\
+83\end{array}$ & $\begin{array}{l}60 \\
63\end{array}$ & l. per min. & $\begin{array}{r}87 \\
71 \\
66 \\
+63 \\
68 \\
+76\end{array}$ & $\begin{array}{l}c c . \\
50 \\
77 \\
84 \\
88 \\
87 \\
65\end{array}$ & $\begin{array}{c}\text { l. per min. } \\
4.3 \\
5.5 \\
5.6 \\
5.5 \\
5.9 \\
4.9\end{array}$ \\
\hline
\end{tabular}

* Omission of figures under Upright indicates that tilting was directly from horizontal to head-down.

+ Average of three consecutive measurements.

$\ddagger$ Average of two consecutive measurements.

had been produced in the limbs prior to the tilt and the rise in pressure upon release of such venous obstruction during the head-down tilt.

\section{Ballistocardiogram in the head-dozen position}

As measured by the ballistocardiogram, the cardiac output usually increased in the inverted position whether or not there was a decrease in pulse rate (Table III). Stroke volume increased, but more markedly when the pulse rate was definitely decreased. Similar increases in stroke volume in the head-down position have been reported by Asmussen and his associates (9) using the acetylene method of Grollman. A slight change in form of the ballistocardiogram was sometimes noted in the head-down position, and this change occasionally persisted for a variable period after a return to the horizontal position. It seemed possible that this phenomenon was due either to a shift in the position of the heart, or to a temporary change in the mechanism of cardiac ejection.

\section{Effects of the head-dowen position on renal func- tion}

Since, as noted above, adaptation to the headdown position was associated with evidences of a vasodepressor response, it was of interest to determine whether the renal circulation participated in the response. This seemed especially

TABLE IV

Renal function in different postures

\begin{tabular}{|c|c|c|c|c|c|c|c|c|c|c|}
\hline \multirow{2}{*}{ Subject } & \multicolumn{3}{|c|}{$\begin{array}{c}\text { Control } \\
\text { (horizontal) }\end{array}$} & \multicolumn{4}{|c|}{ Head-down } & \multicolumn{3}{|c|}{$\begin{array}{c}\text { Recovery } \\
\text { (horizontal) }\end{array}$} \\
\hline & GFR & RPF & FF & $\begin{array}{c}\text { Tilt } \\
\text { position }\end{array}$ & GFR & RPF & FF & GFR & RPF & FF \\
\hline $\begin{array}{l}\text { R. L. } \\
\text { H. M. } \\
\text { A. J. } \\
\text { L. K. } \\
\text { O. T. } \\
\text { L. M. } \\
\text { J. C. } \\
\text { H. B. } \\
\text { R. P. } \\
\text { W. B. }\end{array}$ & $\begin{array}{cc}c c . / m i n . \\
100 \\
127 \\
112 \\
111 \\
137 \\
102 \\
133 \\
101 \\
96 \\
167\end{array}$ & $\begin{array}{c}c c . / \min . \\
559 \\
557 \\
793 \\
490 \\
613 \\
547 \\
483 \\
568 \\
370 \\
641\end{array}$ & \begin{tabular}{|c|}
$\%$ \\
17.9 \\
22.8 \\
14.1 \\
22.6 \\
22.3 \\
18.7 \\
27.5 \\
17.8 \\
26.0 \\
26.1
\end{tabular} & $\begin{array}{l}-30^{\circ} \\
-30^{\circ} \\
-30^{\circ} \\
-35^{\circ} \\
-40^{\circ} \\
-40^{\circ} \\
-75^{\circ} \\
-75^{\circ} \\
-70^{\circ} \\
-75^{\circ}\end{array}$ & $\begin{array}{c}c c . / m i n . \\
116 \\
132 \\
109 \\
102 \\
95 \\
80 \\
147 \\
94 \\
97 \\
146\end{array}$ & $\begin{array}{c}c c . / \min . \\
561 \\
639 \\
712 \\
439 \\
551 \\
482 \\
450 \\
554 \\
373 \\
535\end{array}$ & \begin{tabular}{|c|}
$\%$ \\
20.7 \\
20.7 \\
15.3 \\
23.3 \\
17.2 \\
16.6 \\
32.6 \\
17.0 \\
26.0 \\
27.3
\end{tabular} & $\begin{array}{cc}c c . / m i n . \\
102 \\
109 \\
107 \\
128 \\
136 \\
95 \\
154 \\
104 \\
94 \\
175\end{array}$ & $\begin{array}{cc}c c . / \min . \\
474 \\
481 \\
608 \\
572 \\
629 \\
550 \\
417 \\
599 \\
454 \\
566\end{array}$ & $\begin{array}{c}\% \\
21.5 \\
22.7 \\
17.6 \\
22.4 \\
21.6 \\
17.3 \\
37.0 \\
17.4 \\
20.7 \\
30.9\end{array}$ \\
\hline Average & 119 & 562 & 21.6 & & 112 & 530 & 21.7 & 120 & 535 & 22.9 \\
\hline
\end{tabular}

GFR is the glomerular filtration rate; RPF, the renal plasma flow; and FF, the filtration fraction or GFR/RPF. Glomerular filtration rate was measured by the inulin or mannitol clearances; renal plasma flow, by the diodrast or sodium para-aminohippurate clearance. All figures represent the average of two or more periods with the exception of H. B., in whom only one period was obtained in the head-down position. 
pertinent in view of the fact that the renal vascular bed is known to participate in the vasopressor reaction to the upright position. During inversion only one of the ten subjects showed an increase in renal blood flow as indicated by clearances of diodrast or of sodium para-aminohippurate, while five showed decreases of 50 to $100 \mathrm{cc}$. per minute. No consistent changes occurred in glomerular filtration rate (clearances of inulin or mannitol) (Table IV). In a few instances there was an increase in the filtration fraction at the end of the period of inversion (Table IV, A. J., J. C., W. B.). This was attributed to emotional factors resulting from the fatigue and discomfort of the head-down position. A marked diuresis occurred in two subjects immediately following inversion. In one (R. L.), the urine flow increased rapidly from an average of $0.9 \mathrm{cc}$. per minute to $7.7 \mathrm{cc}$. per minute, and on return to the horizontal position, fell again to $1.8 \mathrm{cc}$. per minute. In the second subject, the urine flow increased from $1.2 \mathrm{cc}$. per minute during the control period to $3.3 \mathrm{cc}$. during inversion, and returned to $1.2 \mathrm{cc}$. in the horizontal position. The cause of this phenomenon was obscure; it was not observed in any of the other subjects.

\section{DISCUSSION}

The data reported above throw light on the hemodynamic alterations that occur early after a tilt into the head-down position. The immediate changes of pressure in the arteries are apparently passive, with increases in the dependent cranial areas and decreases in the up-tilted lower extremities. The decreases in pressure in the legs and feet must be nearly to atmospheric since the hydrostatic distances from the reference points in the thorax (or in the femoral arteries) are equivalent to or greater than the pressures at those points. This undoubtedly accounts for the marked ischemia in the uptilted lower extremities. However, the increases of arterial pressure in the head are less than might be supposed to occur, since the point in the body where pressure remains essentially unchanged as a result of the purely passive, elastic and hydrostatic effects (immediate zero reference point) lies at about the diaphragm considerably nearer the head than the feet. In addition, the pressure is further moderated by a sec- ondary decline, apparently due to vasodilatation in regions other than the renal.

Cerebral venous pressure likewise is increased in the head-down position as the result of hydrostatic forces, but, again, is minimized by certain moderating mechanisms. The chief of these seems to be the circumstance by which the column of blood in the central great veins is interrupted at about the level of the heart, thus diminishing the hydrostatic effect of blood superior in space to that point. Similarly, in the dog the central venous reservoir appears to be divided into two hydrostatically separate chambers, presumably by the pumping action of the heart, since ligation of the inferior vena cava was found by Clark, Hooker, and Weed (10) not to affect the change in jugular venous pressure produced by tilting the animal headdownward. Although in man this separation is less complete, it is nonetheless real. However, despite this, and other possible buffering responses, the increases of pressure are percentilely much greater in the veins than in the arteries of the head in the inverted position.

The renal clearance studies failed to reveal significant changes in renal circulation in the headdown position. One subject, usually hypertensive, although at the time of study normotensive, had an increase in blood pressure to hypertensive levels during the brief period of inversion. However; she showed no change in renal blood flow. Except for this instance, there was no evidence of vasoconstriction in the kidneys during inversion. The failure of the kidneys to participate in the vasodepressor response to the head-down position is consistent with their failure to undergo reactive hyperemia, or to exhibit vasodilatation after the administration of certain drugs, such as acetyl $\beta$-methyl choline (11) or histamine (12).

\section{A NOTE ON SOME MEASURES DESIGNED TO RELIEVE CRANIAL CONGESTION IN THE HEAD-DOWN POSITION}

It seems probable from the results reported above that much of the discomfort and most of the ill effects of negative $G$ arise from the markedly increased pressure in the cranial veins, and its retrograde extension into the capillaries with resultant hemorrhagic phenomena. For example, 
one subject in this study who had been taking sulfonamides, developed a diffuse petechial rash over the neck and face as a result of the inversion. Similar petechiae have been reported routinely to follow exposure to several negative $G$ in aircraft. These considerations led to an exploration of methods by which the marked increases in cerebral venous pressure found normally during bodily inversion might be modified (1).

The ability to reduce cranial venous congestion in the head-down position by blocking the reflux of blood from the limbs with pressurized cuffs, has been described above. This procedure had a definite protective value which was readily appreciated by the subject, although its quantitative effect as measured was relatively small. The application of pressure in an abdominal girdle, prior to inversion, was found in five subjects to have approximately the same effect, namely, to reduce internal jugular venous pressure in the inverted position by 5 to 15 millimeters of mercury.

A pneumatic cuff, designed to apply pressure over the lateral aspect of the neck also was tested, and found when inflated properly, immediately before inversion, to protect the internal jugular (and the cerebral) veins from the high pressures ordinarily produced immediately by the headdown position. The chief objections to this method were discomfort (greater than that due to the inversion at $-1 \mathrm{G}$ alone) and its limited time of effectiveness ( 10 to 30 seconds) before the occurrence of an equal or greater rise in jugular venous pressure due to the prevention of blood flow from the head by the cuff.

Finally, the Müller experiment, or the act of inspiring forcibly against a fixed resistance (best achieved by attempting to breath in, either during deglutition, or after tightly shutting the lips and pinching off the nose), was found to be effective in lowering the internal jugular venous pressure during the rises usually found in the inverted position. It also lowered arterial pressure initially, and usually for as long as it was held, although in one subject it caused an acceleration of the pulse and a secondary rise in arterial pressure above the previous levels. If the maneuver was done prior to and sustained during the head-down tilt there was little, if any, discomfort or visible congestion in the head. If done during a head-down tilt, there was remarkable relief, both subjectively and objectively, of cranial congestion.

\section{SUM MARY}

Studies of the circulatory effects of the headdown position have revealed venous, and to a lesser extent, arterial hypertension in the head to be among the more important changes. Because of moderating physiological mechanisms, the increase in cerebral venous pressure in the inverted position is less than might otherwise be expected, but is still formidable, and presumably the chief cause of the ill effects reported to follow exposure to higher negative $G$. In the inverted position there was a decreased, and often irregular pulse rate, and an increased cardiac output (ballistocardiographic). After the initial passive (hydrostatic) change in arterial pressure there was a further moderate decrease, indicating vasodilatation. A study of renal clearance showed that the kidneys did not participate in this vasodepressor response. Several simple methods of lessening cranial venous hypertension in the head-down position were found to give considerable relief from the usual symptoms and signs of cranial congestion caused by this posture.

\section{BIBLIOGRAPHY}

1. Wilkins, R. W., Bradley, S. E., and Friedland, C. K., Circulatory effects of the head-down position (negative G) in normal man, and measures designed to counteract them. Final Report, Contract OEMcmr 143, May 8, 1946.

2. Green, R. S., Iglauer, A., and McGuire, J., Alterations of radial or brachial intra-arterial blood pressure and of the electrocardiogram induced by tilting. J. Lab. \& Clin. Med., 1948, 33, 951.

3. Hamilton, W. F., Brewer, G., and Brotman, I., Pressure pulse contours in the intact animal. I. Analytical description of a new high frequency hypodermic manometer with illustrative curves of simultaneous arterial and intracardiac pressures. Am. J. Physiol., 1934, 107, 427.

4. Cournand, A., Riley, R. L., Breed, E. S., Baldwin, E. DeF., and Richards, D. W., Jr., Measurement of cardiac output in man using the technique of catheterization of the right auricle or ventricle. J. Clin. Invest., 1945, 24, 106.

5. Wilkins, R. W., A tilting ballistocardiograph. Am. Heart J., 1943, 26, 351.

6. Starr, I., Rawson, A. J., Schroeder, H. A., and Joseph, N. R., Studies on estimation of cardiac output in man, and of abnormalities in cardiac 
function, from heart's recoil and blood's impacts; the ballistocardiogram. Am. J. Physiol., 1939, $127,1$.

7. Goldring, W., and Chasis, H., Hypertension and $\mathrm{Hy}$ pertensive Disease. The Commonwealth Fund, New York, 1944, p. 195.

8. Wilkins, R. W., Bradley, S. E., Culbertson, J. W., and Judson, W. E., Studies to be published.

9. Asmussen, E., Christensen, E. H., and Nielsen, M., The regulation of circulation in different postures. Surgery, 1940, 8, 604.
10. Clark, J. H., Hooker, D. R., and Weed, L. H., The hydrostatic factor in venous pressure measurements. Am. J. Physiol., 1934, 109, 166.

11. Alexander, W. F., and Kotkis, A. J., Responses of the kidney to reflex and direct stimulation of the splanchnic nerve. Proc. Soc. Exper. Biol. \& Med., 1937, 36, 619.

12. Reubi, F. C., and Futcher, P. H., The effects of histamine on renal function in hypertensive and normotensive subjects. J. Clin. Invest., 1949, 28, 440. 